\title{
Como salvar a educação (e o sujeito) pela literatura: sobre Philippe Meirieu e Jorge Larrosa
}

\author{
Flávio Henrique Albert Brayner
}

Universidade Federal do Pernambuco, Programa de Pós-Graduação em Educação

Numerosos artigos lançados nestes dez últimos anos em revistas especializadas em educação nos Estados Unidos, na França e no Brasil, assim como vários livros, dão mostra de um interesse crescente dos educadores por uma aproximação entre literatura e educação. Não se trata mais de procurar na literatura nacional ou estrangeira, clássica ou contemporânea, "temas" escolares ou pedagógicos tratados de forma romanesca, que descrevem os pontos de vista dos escritores sobre a escola de seu tempo, as (des)venturas da experiência escolar dos autores, a denúncia do tradicionalismo, do autoritarismo e da doutrinação dos sistemas pedagógicos de uma certa época a partir da produção literária. Trata-se, antes, de uma produção pedagógica que procura nos textos ficcionais os instrumentos de reflexão que possam ou ajudar a formação dos futuros educadores, ou estabelecer uma forma de diálogo silencioso capaz de proporcionar uma espécie de autoconstrução de si (perdão pelo pleonasmo) a partir de diferentes perspectivas permitidas pela substância literária: uma singularização no interior de um mundo plural, uma capacidade de escolha, de julgamento e de decisão a partir de um ponto de vista descentrado que a literatura poderia fornecer.

Nanine Charbonnel, professora da Universidade de Strasbourg, por exemplo, sustenta que o texto literário "deveria fazer parte integrante de um estudo do pensamento pedagógico. A hora ainda não chegou em que um tal estudo se imporia em nossos cursos de educação, mas ela chegará" (Charbonnel, 1991, p. 112). ${ }^{1}$ A autora de As aventuras da metáfora não está só na empresa de adoção do texto ficcional na formação educacional. Philippe Meirieu, por exemplo, considera que "a literatura pode nos permitir apreender a experiência singular de toda empresa educativa [...] criar uma disposição de espírito apto a estabelecer escolhas em um universo marcado pela pluralidade das experiências e dos dados" (Meirieu, 1999, p. 12).

De uma maneira geral, diria que esse interesse recente pela literatura por parte de tantos educadores assinala uma espécie de cansaço: nas últimas três ou

1 Todos os títulos e citações de originais em língua estrangeira são traduções livres. 
quatro décadas, a discussão pedagógica foi marcada, seja por um sociologismo que tentava demonstrar o enraizamento social (e de classe) de toda prática educativa ou a influência decisiva do meio social de origem sobre a performance escolar dos alunos, seja por um psicologismo que, baseado excessivamente sobre a aprendizagem, transformava a sala de aula em laboratório de aquisição e de desenvolvimento cognitivo. Em reação a um discurso essencialmente "científico" que dava o tom do logos pedagógico, vê-se, agora, a emergência de um humanismo que toma a forma especial, não de uma "educação estética" ( a la Schiller), mas de uma nova relação entre literatura e educação.

Nesse novo entusiasmo produzido por uma possível aliança entre literatura e educação, pode-se encontrar, no entanto, orientações diferentes: a primeira, que chamarei de pedagogização da literatura, retoma, de uma certa forma, a tradição do Bildungsroman, ampliando-a e até mesmo ultrapassando-a em sua forma e em seu conteúdo, mas desejando, na prática, "resultados" semelhantes: uma construção de si por meio de uma viagem acompanhada e refletida cujo fim é uma elevação pessoal que a educação e a instrução não podem proporcionar. Nessa primeira orientação enquadro o professor da Universidade de Lyon II, Philippe Meirieu. A segunda orientação, de inspiração claramente nietzscheana, procura uma solução que chamarei de literaturização da pedagogia. Se no primeiro caso a literatura fornece os elementos para um diálogo interior através da experiência de outros homens (ficcionais ou não), no segundo as ambições são mais amplas: fazer da educação uma reescrita de si, em que o ato educativo exercido sobre si mesmo (como uma espécie de auto-subjetivação) se confunde com a escrita ficcional, na qual a vida e a literatura se interpenetram e tomam a forma de uma "estética da existência". Nessa segunda orientação insiro o professor da Universidade de Barcelona, Jorge Larrosa.

Em seu trabalho sobre literatura e educação, quer dizer, sobre o papel que a literatura pode fazer na formação do educador, Meirieu assinala, desde o início do livro, as deficiências das chamadas "ciências da educação":
Só existe ciência do geral; as ciências da educação estão condenadas a trabalhar sobre vastos conjuntos, a tentar estabelecer regras gerais, tanto sobre o plano das aprendizagens cognitivas como sobre os das condições psicológicas ou sociológicas do sucesso escolar. Elas estão em busca de invariantes e de correlações, recolhem-se prudentemente nas descrições e nas análises dos discursos ou das experiências já realizadas e de quem elas se esforçam para tomar uma certa distância. Saudável precaução científica, mas que distancia, inevitavelmente, as tensões vivas que animam os homens. (Meirieu, 1999, p. 11)

“Tensões vivas" que uma ciência da educação que procura invariantes não pode obter e cujo ponto de Arquimedes é o diálogo (interior e entre subjetividades diferentes) proporcionado pela literatura em um processo de autoconstrução que lembra a longa viagem do Bildungsroman e sua busca de universalidade, como se pode observar em algumas passagens do prefácio do livro em questão:

\footnotetext{
[...] como todos os ofícios humanos, o ofício da educação

[...] não é redutível ao conjunto das competências para exercê-lo. Educar supõe uma arte de fazer". E mais adiante, nos seus "vazios", o texto literário permite ao leitor falar de si mesmo, dialogar com outros homens, em um movimento que já é uma forma de universalidade, à qual deve chegar toda educação que não se limite a "fabricar" algo. (idem, p. 18)
}

Versão contemporânea do Bildungsroman? Estratégia humanista para escapar do logos pedagógico dominante? Saída romântica de uma situação marcada pelo princípio da performance e da utilidade? Solução decadentista ou novo continente que se abre à educação depois da enorme suspeita (pós-moderna) lançada contra o discurso "científico"?

Temo que o desejo - legítimo, aliás - de recorrer à literatura como veículo de formação seja bem mais complexo do que nos deixam crer as nobres intenções de certos educadores. O que é, finalmente, que se "esconde" por trás desse desejo de apelar para a literatura como meio de formação? 


\section{A pedagogização da literatura em Philippe Meirieu: a tensão entre Kultur e Zivilisation}

Em primeiro lugar, a velha distinção alemã entre Kultur e Zivilisation parece-me, neste debate, decisiva. Em seguida, creio que seja necessário levar em conta certos propósitos da estética da recepção (Hans Robert Jauss) para tratar a relação entre o texto ficcional e o leitor, um tema que estimo gravemente ausente das tentativas de aproximar a literatura da formação do educador. Philippe Meirieu será, neste primeiro momento, meu interlocutor privilegiado.

Digamos, para abreviar, que a tradição romântica alemã, erigindo-se contra o racionalismo das Luzes e o classicismo normativista burguês, produziu dois conceitos para designar, de um lado, o mundo espiritual dos valores substantivos (Kultur) e, de outro, um universo material dominado pelo cálculo, o lucro, a produção de mercadorias que o capitalismo havia instaurado (Zivilisation). A arte (e a cultura em geral) estava situada em uma esfera que permitia ao homem, apesar da dominação do mundo industrial, o "vôo do espírito": uma capacidade de deslocar-se do mundo da facticidade para elevar-se além do universo da utilidade e dos valores de troca.

Mas, em que os conceitos de Kultur e de Zivilisation (Hauser, 1951) interessam a um debate sobre o pedagógico (e à utilização da literatura na formação)? Na medida, creio eu, em que eles permitem distinguir duas formas de uso social da Razão (e, portanto, de uma razão pedagógica), a saber: uma razão de tipo "substantiva", capaz de pensar fins e valores sociais de nossas decisões, e uma razão de natureza “instrumental”, performática e finalista. Se aceitarmos o pessimismo weberiano que concebe a modernidade como progresso contínuo de uma Zwerkrationalität, um processo de desencantamento do mundo; se, no domínio pedagógico, somos hoje seduzidos ou constrangidos por discursos que privilegiam a "integração cidadã", a "empregabilidade", a "flexibilidade" ante as novas tecnologias e a "inserção" no mercado; se a pesquisa pedagógica está em vias de tomar um caminho que a leva a acentuar a aprendizagem a partir de formas de cognição mais ou menos controláveis; se, em outros termos, o discurso pedagógico está aderindo às formas instrumentais da razão, de ser absorvido pelo domínio da Zivilisation, pode-se então compreender a intenção de incorporar a literatura na formação do educador: ela é esae esforço tão nobre quanto romântico de recusa de um logos pedagógico de perspectiva claramente performativa e instrumental, tanto quanto uma tentativa de "reencantamento" do discurso pedagógico por meio da reabilitação do ideal da "formação" (Bildung), enquanto auto-subjetivação que escapa, em parte, às possibilidades de controle exterior, já que a narração literária
[...] não diz tudo, em seus interstícios e suas ambigüidades, ela autoriza o leitor a falar dele mesmo, e até em evocar pudicamente a parte mais secreta dele mesmo. Mas ela diz, de qualquer forma, suficientemente para resistir à captura total pelo nosso imaginário e nos reassociar a outros seres humanos, em um movimento de objetivação que esboça uma forma de universalidade. (Meirieu, 1999, p. 16, grifos do original)

Algumas passagens do livro de Meirieu revelam o estado de espírito de um autor que recusa que o pedagógico caia deliberadamente ou ingenuamente nas malhas de uma ordem dominada pela razão instrumental:

Que tristeza ver a escola abandonar progressivamente todo trabalho sobre o simbólico e procurar desesperadamente a justificativa de suas ações nos usos sociais imediatos dos saberes que ela ensina. [...] a formação dos educadores, como a educação das crianças, não tem nada a ver com um processo de fabricação, cujo sucesso seria garantido antecipadamente. (idem, p. 131-132)

Em resumo, o programa de aliança entre a literatura e a educação proposto por Meirieu parece-me a tentativa de resistir à unidimensionalidade (Marcuse) da educação, à sua absorção pela facticidade do presente e de preservar, assim, as possibilidades da Kultur. No entanto, nesse caso poderíamos levantar uma questão de sabor, digamos, adorniano: uma literatura sub- 
metida às injunções do mercado pode ajudar a refletir sobre o papel de uma educação cada vez mais dependente dos apelos desse mesmo mercado?

Minha opinião é que o discurso (pouco) crítico sobre o caráter mercantil da arte (no caso, da literatura) não considera que mesmo os produtos da indústria cultural constituem mercadorias sui generis: é apenas parcialmente que a necessidade estética pode ser manipulada, porque a produção e a reprodução da arte, na sociedade industrial, não chega jamais a determinar a forma da recepção: esta não é um consumo passivo, mas uma atividade estética dependente de aprovação ou de recusa, e, por essa razão, em grande parte não submetida ao cálculo mercantil.

Acontece, no entanto, que esse argumento, no lugar de vir em socorro dos proponentes de uma pedagogização da literatura, abre um novo problema aparentemente negligenciado: a relação entre o leitor do texto ficcional, particularmente aquele que se encontra em formação (para se tornar educador), e uma recepção também particular da literatura que pretende contribuir para essa formação. Aqui observo - ao menos em Meirieu - a ausência de uma teoria da recepção que possa dar conta dessa situação particular. No fim das contas, há uma enorme diferença entre o "simples" leitor de um texto ficcional e o leitor que quero formar a partir do texto literário para exercer uma futura atividade profissional (pedagógica).

\section{O problema da recepção}

Consideremos, de início, o fato de que entre o texto literário e o leitor não existe espaço vazio que possa ser "preenchido" pelas possibilidades interpretativas individuais. Entre os dois se interpõe um conjunto de expectativas, de um lado e de outro, definidas por um horizonte cultural e histórico, uma estratégia midiática, um meio social que valoriza (ou não) certas leituras, um investimento simbólico realizado pelo consumidor de obras literárias etc. Imaginemos, em seguida, que entre o texto literário e o leitor se interponha um leitor, e que esse leitor naturalmente - proponha sua própria leitura e sua pró- pria interpretação (no caso, pedagógica) do texto ficcional. Estaríamos em uma situação em que não apenas transformaríamos nossos estudantes em leitores de "segundo grau" (indiretos), mas na qual a operação de leitura seria dirigida, na seleção das obras e na maneira de tratá-la. Em razão dessa dupla consideração, estou convencido que a relação entre literatura e educação, quer dizer, da literatura na formação do educador, tem necessidade de ser tratada no interior de uma estética da recepção.

Retomemos uma frase de Meirieu que condensa, de uma certa maneira, sua "teoria" da recepção dos textos literários com vista formativa:

Sua eficácia formadora é, no entanto, ligada à distância que eles entretêm com o leitor: muito próximos a ele, correm o risco de suscitar processos de identificação que tornarão difícil a distância crítica. Muito exóticos, eles correm o risco de serem rejeitados, considerados como radicalmente estranhos aos problemas encontrados quotidianamente, e para concluir sua "teoria": porque só existe formação se um conflito sociocognitivo entra em jogo. (Meirieu, 1999, p. 17)

Essa posição coincide com a de Wolfgang Iser, para quem a função social dada ao texto literário é a de questionar o saber a priori do leitor e assim forçálo a um diálogo interior (Iser, 1979). No entanto, na concepção de Iser, é o texto literário per si que realiza essa tarefa, e não um leitor interposto. E um leitor, no caso de Meirieu, muito especial!

"Especial" na medida em que ele realiza uma leitura "pedagogizante" do texto literário, abandonando, por exemplo, a dimensão do prazer estético. Para Meirieu, a obra ficcional surge como uma função-meio: permitir aos outros o "crescer" com as experiências relatadas por alguns autores escolhidos (e isso a despeito do fato de que essas experiências não são tratadas pelos autores como pertencendo à ordem do "crescer"). ${ }^{2}$

\footnotetext{
2 O que pode implicar um caso de "sobreinterpretação"
} (Umberto Eco), situação em que se ultrapassa os limites interpretativos impostos pela própria materialidade do texto. 
A palavra "pedagógica", associada às obras literárias, parece constituir uma etiqueta pouco honorável (para os autores, claro!), e poucos escritores aceitariam classificar seus trabalhos como "pedagógicos". A literatura é algo que se anuncia como radicalmente produtora de uma realidade e de uma subjetividade que não têm outro modo de existência a não ser o estritamente literário. É o que Larrosa chama de "radical impossibilidade de subordinação da literatura". O que significa que o caráter pedagógico de uma obra de ficção é essencialmente um efeito de leitura, uma vez que toda narrativa literária, toda obra de ficção, pode ser lida a partir do pressuposto de que ela contém um ensinamento, mesmo se isso está longe de esgotar todas as suas dimensões (Larrosa, 2000, p. 45). A "pedagogicidade" de um texto depende, em suma, das condições de leitura: o pedagógico deve ser procurado, antes de qualquer coisa, no... pedagógico, e só secundariamente na literatura. $O$ problema surge quando a um efeito de leitura especial (pedagogizante) se associa a escrita do formador que oferece ao leitor (ele também especial) uma grade de leitura determinada, uma interpretação já estruturada que subordina a obra e o leitor. Doravante, não se trata mais de um leitor aberto e desconhecido, mas um leitor orientado na sua leitura, dirigido na sua modalidade de recepção.

No caso da literatura, o problema é ainda mais complexo porque leituras administradas, "já lidas", já interpretadas, alimentam o quadro contraditório (e moderno!) de uma comunicação intersubjetiva colonizada por ações de natureza finalista. E, além disso, não poderíamos estar mais próximos, mesmo que seja num segundo grau, do Bildungsroman, em que estamos lidando com uma autotransformação: a do autor e dos seus estudantes. Romantismo e "instrumentalismo" aliam-se numa estranha receita emancipatória!

Em um outro registro, e com o objetivo de estabelecer as relações entre o texto ficcional e o leitor a partir de um perfil de recepção já orientado pelo perfil do texto, Karlheinz Stierle (1979), em seu ensaio “Que significa a recepção de textos ficcionais?", opera uma distinção que considero importante nesse debate: a distinção entre recepção pragmática e recepção ficcional. Para esse autor, parece indispensável ultrapassar a idéia de uma recepção puramente material e baseada na facticidade do texto, para sublinhar o perfil da recepção: "a questão da especificidade da recepção é, antes de tudo, a questão da especificidade de sua construção" (Stierle, 1979, p. 136). No lugar de tomar o texto como uma constante que produz uma vasta gama de recepções, ele procura revelar a constância no outro pólo, de maneira a obter as condições de melhor descrever a interação texto-leitor. Daí sua distinção entre recepção pragmática e recepção ficcional, cada uma correspondendo a um texto da mesma ordem (texto pragmático e texto ficcional). O texto pragmático é aquele que apresenta um estado de fato, quer dizer, uma interpretação que oferece um modo de orientação quanto à situação dada, interpretação chamada de "elementar" porque o texto propõe se tornar um trampolim para a ação. O texto pragmático deve ser "programado" para que seu leitor possa recebê-lo de acordo com um esquema de ação previamente conhecido tanto pelo autor quanto pelo leitor, que participam, ambos, do mesmo saber social. Em resumo, ambos, de uma certa maneira, prevêem seus respectivos papéis: o produtor sabe o que espera dele o receptor e este sabe o que aquele deve lhe oferecer. ${ }^{3}$ Nesse sentido, escreve Stierle, "visando o campo da ação, o texto pragmático se orienta para um além dele mesmo" (Stierle, 1979, p. 112).

No campo ficcional (texto e recepção), muda-se de direção, porque não se pode afirmar que a ficção

${ }^{3} \mathrm{O}$ texto (e a recepção) pragmático coloca, assim, fora de propósito toda tentativa de produzir, no leitor, um conflito "sociocognitivo", fundamental na "teoria" da recepção de Meirieu. Intervindo entre o leitor e a obra com uma interpretação pedagógica, Meirieu não somente "prepara" seu leitor em vista de uma recepção determinada (sobretudo o leitor que não tem acesso à obra original), mas ele já sabe a quem se dirige. O leitor, por sua vez, alimenta igualmente as expectativas de uma recepção pedagógica do texto. 
remete ao campo da ação. Como diz ainda Stierle, "os textos ficcionais são, no sentido próprio do termo, textos de ficção somente quando se pode contar com a possibilidade de um desvio (do que é oferecido pelo texto), desvio, na verdade, não submetido à correção, mas somente interpretável ou criticável" (idem, p. 114-115), que permite uma nova manipulação, seja dos conceitos, seja das experiências, deixando ao leitor as oportunidades de experiência não previstas pela recepção pragmática.

Se a distinção esboçada é válida, então o livro de Meirieu, que se coloca na interposição entre o leitor eventual (seus estudantes) e a obra (o leitor que fala de si e de suas leituras e nos dá uma interpretação pedagogizante), termina por transformar uma recepção ficcional em recepção pragmática, situação não prevista no ensaio de Stierle. Transformada em função-meio com vistas ao "crescer", o texto literário sai de sua órbita ficcional para ser absorvido por um universo instrumental, situação que termina por esvaziar o potencial de Kultur compreendido na obra de arte. Um efeito perverso absolutamente indesejável, se levarmos a sério as pretensões do nosso autor.

\section{"Estetização da pedagogia" em Jorge Larrosa: a tensão entre sociedade administrada e "estilística de si"}

E, curiosamente, desde que entramos numa era "pós-metafísica", tudo parece ter se transformado em ficção. Se, como deseja Lyotard, a pós-modernidade define-se por uma incredulidade em relação às metanarrativas totalizadoras, essa suspeita parece ter produzido um efeito inesperado: um retorno ao "todo-narrativo"!

\section{Paul Ricoeur dizia em Temps et récit que}

[...] nossa própria existência não pode ser separada do modo pelo qual nós podemos nos narrar. É contando nossas histórias que nos damos uma identidade. [...] E não há muita diferença se essas histórias são verdadeiras ou falsas: tanto a ficção quanto a história verificável são construções identitárias. (Ricoeur, 1985, p. 213).
Michel Foucault (1977), em uma entrevista à Quinzaine Littéraire, afirmava:

Eu me dou conta de que só escrevi ficções. Eu não quero dizer que esteja faltando com a verdade. Parece-me que existe a possibilidade de fazer funcionar a ficção na verdade; de induzir efeitos de verdade com um discurso ficcional e de fazê-lo de tal maneira que o discurso de verdade suscite, "fabrique" qualquer coisa que não existe ainda, que "ficcione".

O próprio Meirieu (1999) termina seu livro com a frase: "Cada um vê bem que o pedagógico se situa resolutamente no interior da ficção".

É verdade que a narração, especialmente a narração romanesca, abrindo a possibilidade de que novos narradores retomem e reinterpretem os eventos, em uma história sem fim, em uma "obra aberta", conduz ao "paraíso imaginário dos indivíduos. É o território onde ninguém é possuidor da verdade, nem Anna nem Karenina, mas onde todos têm o direito de ser compreendidos" (Kundera, 1989, p. 192). Mas daí a supor que tudo é ficção, que toda "política da verdade" não passa de um esquecimento daquilo que foi originalmente uma metáfora (que uma vez esquecida tornou-se verdade) me parece um exagero, uma aplicação desmesurada do perspectivismo nietzscheano, sobre um fundo de intenções democráticas. E é exatamente daí que parte a "literaturização da pedagogia" de Larrosa (Larrosa, 2000, p. 56).

Em Leitura e metamorfose, nosso autor constrói uma interpretação sensível e inteligente do poema de Rilke "O Leitor" (Der Leser), no qual o núcleo da análise se situa em uma certa idéia de leitura; "a relação entre o presente do texto e o ausente, entre o dito e o não dito, entre o escrito e o além do escrito: a leitura se colocaria justamente em um modo onde o presente assinala o ausente, o sentido se situa além do escrito" (Larrosa, 2000, p. 110). Trata-se, como em Meirieu, de uma leitura que deve modificar o leitor, na qual este deve se fazer indiferente ao primeiro ser (o "mundo administrado"), subtraído de sua origem e arrancado ao que pode lhe confortar. 
Mundo administrado! ${ }^{4}$ Nesse ponto o professor da Universidade de Barcelona aproxima-se, ainda uma vez, das posições de Meirieu. Não no sentido de que a literatura deve promover o "vôo do espírito" para além das injunções do presente, mas no sentido de que uma educação estritamente associada às exigências do mercado, da performance, da competência técnica, é apenas "fabricação". Se ontem tínhamos necessidade de libertar os homens das ilusões e das sombras, da ideologia e da "consciência ingênua", hoje é necessário livrá-lo da "sociedade administrada". E como fazê-lo? Curiosamente, não mais pela filosofia ou por uma ação política "transformadora", mas por uma ação sobre si mesmo, uma auto-interpelação proporcionada pela literatura. Com a literatura podemos, finalmente, dispor de um novo instrumento soteriológico, menos ambicioso, talvez, mas também menos ofensivo que a razão e a política.

Nós que contemplávamos o leitor, pertencíamos ao mundo administrado: nós estávamos seguros de nossa identidade, nós sabíamos quem nós éramos; [...] para nos tornarmos o que nós somos, para dominar o tempo e contá-lo, para saber o que são as coisas, para manipulá-las segundo nossa vontade, nós recorríamos às horas de curso, aos espaços e ao tempo que o mundo administrado e interpretado acionou para nos converter naquilo que somos e para fazer de nós os habitantes securizados do primeiro mundo (o mundo administrado). (Larrosa, 2000, p. 115)

Não se poderia ser mais claro: trata-se de denunciar o caráter normalizador, doutrinário, disciplinar e disciplinador do logos pedagógico, de suas injunções moralizadoras, progressistas e otimistas, o que, pessoalmente, considero perfeitamente aceitável numa época que não quer (ou não pode) mais alimentar certas ilusões de uma pedagogia Aufklärer. O problema é que o ataque ao discurso pedagógico utiliza a mesma ordem de discurso (analítico, proposicional, sal-

${ }^{4}$ A expressão vem de Adorno e Horkheimer, e fez fortuna nas páginas de Marcuse ("sociedade administrada”). vacionista) que fez da pedagogia um discurso, um logos. Enfim, se, como queria Benjamin, sustentar uma perspectiva revolucionária exige uma fuga da esfera do "progresso", 5 tal como concebido pelas Luzes, e, se criticar a esperança igualmente Aufklärer da auto-emancipação do espírito e da autoconsciência pela educação é a maneira larrosiana de sustentar o otimismo em uma possibilidade emancipatória (da sociedade administrada), então o que nós expulsamos pela porta da frente, retorna pela de trás: continuamos "progressistas" e "otimistas"!

Pode-se encontrar a base da "pedagogia profana" de Larrosa na célebre frase de Nietzsche que nosso autor "não resiste em transcrever":

No entanto, o que é a verdade? Uma multidão em movimento de metáforas, metonímias, antropomorfismos; em uma palavra, um conjunto de relações humanas que, elevadas, transpostas e enfeitadas poeticamente e retoricamente, após um longo uso, o povo considera como sólidas e canônicas: as verdades são ilusões que esquecemos, metáforas já utilizadas que perderam sua força sensível.. (Nietzsche apud Larrosa, 2000, p. 123)

Eis porque Larrosa não pode falar de "projeto", já que isso implicaria a aceitação do logos pedagógico dominante, quer dizer, o estabelecimento de uma relação patológica com o saber (e não com a vida), fazendo da pedagogia uma forma perversa e imperial de relação com a verdade, o progresso, a ordem e a disciplina.

A literatura participa, assim, na concepção de Larrosa e na ausência de um "projeto" de uma solução pedagógica estetizante. A questão não é mais a de saber se a possibilidade de reinvenção do sujeito a partir de bases não-cognitivas é realizável no interior de uma instituição (a discussão de Larrosa não passa pela escola); essa discussão estaria, antes, situada nas

${ }^{5}$ Cf. Teses sobre a filosofia da história (São Paulo: Ática, 1995), particularmente a análise benjaminiana do quadro de Paul Klee, Angelus Novus. 
balizas daquilo que as vanguardas estéticas realizaram no início do século que findou: uma reformulação radical da linguagem que possa "redescrever" o sujeito fora dos vícios, das patologias e das perversões de uma linguagem incapaz de admitir o impensável, o desviante, a recriação de si a partir de uma "política de renomeamento" (uma espécie de Buendía pedagógico, a dar nome a um mundo virgem e primevo). Em resumo, nada de autonomia sem uma mudança radical da linguagem pedagógica.

Se, ladeira acima, as idéias de Larrosa vão procurar inspiração em Nietzsche, ladeira abaixo elas se juntam às de um outro nietzscheano: Michel Foucault.

Foucault (1984, p. 23): "Eu fui levado a substituir uma história dos sistemas de moral, que seria feita a partir de interdições, por uma história das problematizações éticas a partir das práticas de si”. Em $O$ cuidado de si, Foucault (1985) lembra o papel do sonho erótico (Artemidoro, Pseudo Luciano, Marco Aurélio) para mostrar como a moral se modifica em uma conversão a si, e como o modo de subjetivação transforma-se com o estoicismo. Quer dizer, como a idéia de uma construção de si é, ao mesmo tempo, permanente e histórica, cada civilização criando sua estética da existência. O problema não é mais o de "descobrir" o que somos, mas o de "recusar" o que fizeram de nós. O "projeto", por assim dizer, é o de uma "estilística de si”, uma construção de sua própria vida como uma obra de arte. Esse exercício seria, assim, uma forma de nos assinalar as inumeráveis maneiras que temos de nos construir por meio de uma nova formação do corpo, uma nova relação entre os homens, uma nova representação do prazer, uma nova inserção na cidade. Trata-se, num sentido não muito preciso, de uma autopedagogia.

E, no entanto, não posso me impedir de ver nesse tipo de exercício qualquer coisa de decadente. ${ }^{6}$ Como se as soluções (existencialmente) estetizantes e altamente individualistas surgissem sempre naqueles mo-

${ }^{6}$ Eu não tomo a expressão em um sentido negativo ou pejorativo, já que a "decadência" é também anunciadora de algo novo. mentos em que "nós não somos mais, mas também não somos ainda": solução que reflete um profundo mal-estar e que nos torna vulneráveis seja à aquisição de "eus" postiços, seja a um narcisismo patológico, mais voltado para o consumo de si que para a construção subjetiva. Um mal-estar que, na verdade, se encontra na origem do dandismo, da boêmia, do anarquismo como estilo de vida. Em suma, do marginal, em profundo desacordo com um mundo que não o compreende, mas do qual ele gostaria de gozar todas as benesses, com um mínimo de compromisso.

Larrosa:

Somente o combate das palavras ainda não pronunciadas contra as palavras já pronunciadas permite a ruptura do horizonte dado, permite ao sujeito se inventar de outra forma, que o "eu" seja um "outro". [...] Somente assim podese escapar, ainda que provisoriamente, da captura social da subjetividade. (2000, p. 78)

Essa conversão-a-si faz-se, segundo Larrosa, pela leitura, sendo seu veículo a obra literária. A leitura surge, assim, como o trabalho de autoconstrução subjetiva não determinada pelas "coisas ditas", um "eu" que se forja na forma de uma viagem interior e exterior "como uma experiência estética".

Um ponto central dessa experiência concerne à capacidade de "estranhamento" e de "ad-miração" (Thaumadzein): uma capacidade que muitos autores já atribuíram às crianças.

Na interpretação que Larrosa nos oferece de Rilke (Elegias de Duyno e Sonetos a Orfeu), as crianças jogam um papel essencial porque elas "desconhecem o passado e o futuro", justamente por seu

[...] incompleto pertencimento ao mundo interpretado. [...]

Os olhos desinteressados do leitor, batendo contra um mundo

No entanto, esse tipo de "solução" estética aparece sempre onde não conseguimos resolver os conflitos sociais ou políticos nas esferas que lhes são próprias. De qualquer modo, em sociedades desiguais e hierárquicas como a nossa, ela se constitui numa solução elitista e exclusivista. 
pleno e terminado seriam olhos que adquiriram qualquer coisa do olhar pueril de uma criança. [...] Assim, com esse olhar, viver o existente não é mais distinguir, classificar e ordenar o mundo interpretado e administrado, não é mais julgar nem qualificar coisas [...], mas deixar aparecer o existente em seu ser, em sua plenitude e sua distância, quer dizer, em sua verdade. (Larrosa, 2000, p. 69)

Se ontem era o olhar advertido e percuciente do platonismo que permitia um acesso às coisas situadas além das aparências, hoje é o olhar ingênuo e parvo, não contaminado por essa ortopedia visual proposta pelas Luzes, que nos proporcionará a verdade. Nós estamos, além do mais, diante de uma concepção de "leitura" que vai completamente de encontro àquela proposta por Meirieu: um sugere o "crescer", o outro um retorno (?) ao "olhar pueril".

Pessoalmente, tenho algumas dificuldades em aceitar essa ficção projetada sobre uma infância cujo olhar permaneceria impermeável à sociedade administrada. Um autor que elabora um sofisticadíssimo programa proposicional, que sustenta uma "tese" sobre a recepção da obra poética e alimenta expectativas futuras (se transformar pela leitura) (Larrosa, 2000, p. 112), pode ser tudo, menos uma "criança"! Tem mais: a sociedade administrada não é qualquer coisa que se situaria "do outro lado", no exterior, produzindo e formatando identidades por meio das tecnologias de subjetivação; enquanto "deste lado" se encontrariam aqueles que propõem um novo logos pedagógico, os portadores de uma super visão sobre os mecanismos da subjetivação impostos pelo "sistema", dos quais não podemos nem mesmo suspeitar, porque os instrumentos de que dispomos são justamente aqueles fornecidos pela própria ordem administrada. Como, então, o perceberíamos? E por que alguns detêm as condições de recuo crítico e de "estranhamento" que outros não possuem?

\section{Para concluir...}

Nas suas Conferências sobre a psicanálise, Freud afirmava que o leitor de romances
[...] pode se dar abertamente às emoções normalmente recalcadas, porque seu prazer tem como pressuposto a ilusão estética, quer dizer, o alívio de sua dor pela segurança de que, primeiro, trata-se de um outro que sofre e, em seguida, de que trata-se simplesmente de um jogo que não pode causar nenhum dano à nossa segurança pessoal. (Freud, 1976, p. 235)

Embora a catarse aristotélica não resuma toda a relação entre a arte e seu consumidor, a frase freudiana pode nos lembrar, muito oportunamente, que a obra literária é antes de tudo... obra literária, e que toda recuperação pedagogizante dela não passa de uma forma de controle de sua recepção, uma maneira de administrar a ficção.

Embora com olhares diferentes, Meirieu e Larrosa pactuam da mesma crença no poder formador e regenerador da literatura, mesmo que divirjam em pontos fundamentais: Meirieu propõe leituras “já lidas", administradas, com fins precisos; Larrosa, a recusa da recepção dirigida da obra ficcional. Ambos estão em profundo desacordo com um mundo cuja exigência maior ata-se à utilidade e à performance. No fundo, penso que reside em tudo isso um ataque sistemático contra a modernidade, que termina sempre, após algumas peripécias, em sua estrita identificação com a danada da "razão instrumental", imperdoável traição das Luzes, causa de nosso mal-estar profundo. Há, no entanto, em nossos dois autores, a intenção subterrânea de todo reformador educativo: redescrever subjetividades! Resta saber se a literatura poderá fornecer os predicados necessários a essa redescrição e, se assim fazendo, não estará se transformando numa nova - e ainda mais sofisticada - "tecnologia do eu".

FLÁVIO HENRIQUE ALBERT BRAYNER, doutor em educação pela Universidade de Paris V-René Descartes e com pósdoutorado pela Universidade de Paris VIII-Saint-Denis, é professor no Programa de Pós-Graduação em Educação da Universidade Federal de Pernambuco. Atua também como maître de conférences invité da Université Paul Valéry-Montpellier III. Publicações mais importantes: Ensaios de crítica pedagógica (Campinas: Autores Associ- 
ados, 1985); "Littératurisation" de la pédagogie et "pédagogisation" de la littérature (Revue Française de Pédagogie, Paris: INRP, no 137, décembre 2001, p. 27-35); Da criança cidadã ao fim da infância (Revista Educação e Sociedade, Campinas, CEDES, n 76, 2001, p. 197-211); Pesquisa atual: Política e educação na obra de Hannah Arendt. E-mail: flaviobrayner@hotmail.com

\section{Referências bibliográficas}

CHARBONNEL, N., (1991). Les aventures de la métaphore. Strasbourg: Presses Universitaires de Strasbourg.

FOUCAULT, M., (1977). Les rapports de pouvoir passent à l'intérieur du corps. Quinzaine Littéraire, Paris, n 247, p. 34-48.

, (1984). Histoire de la sexualité - v. 3: le souci de soi.

Paris: Gallimard.

, (1985). História da sexualidade III: o cuidado de si. Rio de Janeiro: Graal.

FREUD, S., (1976). Conférences sur la psychanalyse: ebauche sur la fantasie. Paris: La Pleiade.
HAUSER, A., (1951). The social history of art. London: Routlege and Keagan Paul.

ISER, W., (1979). A interação do texto com o leitor. In: LIMA, L. C. A literatura e o leitor: textos de estética da recepção. Rio de Janeiro: Paz e Terra, p. 134-167.

KUNDERA, M., (1989). L'art du roman. Paris: Folio-Gallimard. LARROSA, J., (2000). Pedagogia profana. Belo Horizonte: Autêntica.

LIMA, L. C., (1979). A literatura e o leitor: textos de estética da recepção. Rio de Janeiro: Paz e Terra.

MEIRIEU, P., (1999). Des enfants et des hommes: littérature et pédagogie - v. 1. Paris: ESF.

RICOEUR, P., (1985). Temps et récit-v. 3. Paris: Éditions du Seuil. STIERLE, Karlheinz, (1979). Que significa a recepção de textos ficcionais? In: LIMA, L. C. A literatura e o leitor: textos de estética da recepção. Rio de Janeiro: Paz e Terra, p. 183-187.

Recebido em dezembro de 2004 Aprovado em abril de 2005 


\section{Resumos/Abstracts}

Flávio Henrique Albert Brayner

Como salvar a educação (e o sujeito) pela literatura: sobre Philippe Meirieu e Jorge Larrosa

A tentativa de aproximação entre literatura e educação está encontrando um número cada vez maior de adeptos. Isso parece indicar a emergência de um novo logos pedagógico que tenta, talvez, ultrapassar as fronteiras de reflexão impostas pelas "ciências da educação". Algumas dessas tentativas, no entanto, apresentam certas (e compreensíveis) limitações, como a ausência de uma "teoria da recepção" dos textos ficcionais, mas, em outros casos, demonstra a ambição de revolucionar o discurso pedagógico por intermédio da literatura, na qual a própria pedagogia se transforma em projeto de "estetização da existência". Tomando Philippe Meirieu e Jorge Larrosa como ilustrações das "limitações" e da "ambição revolucionária", respectivamente, o artigo procura mostrar como romantismo e nietzscheanismo tentam constituir um novo discurso que pretende, uma vez mais, nos salvar da "sociedade administrada".

Palavras-chave: literatura; educação; estetização da existência; Philippe Meirieu; Jorge Larrosa.

How to save education (and the subject) using literature: on Philippe Meirieu and Jorge Larrosa An increasing number of students are now attempting to bring literature and education closer together. This seems to indicate the emergence of a new pedagogical logos, which attempts perhaps to overcome the frontiers of reflection imposed by the so-called "sciences of education". Some of the approaches, however, not only display visible and understandable limitations, such as the absence of a reception theory of fictional texts, but also demonstrate the ambition of revolutionising pedagogic discourse through literature by transforming it into an aesthetics of existence project. Taking Philippe Meirieu and Jorge Larrosa as illustrations of the "limitations" and "revolutionary ambition" respectively this paper seeks to show how Romanticism and Nietzscheism attempt to build a new discourse, which aspires to save us, yet again, from the evils of the "managed society".

Key-words: Literature; education; aesthetics of existence; Philippe Meirieu; Jorge Larrosa 